\title{
Prediction of the Limiting Oxygen Index Using Simple Flame Extinction Theory and Material Properties Obtained from Bench Scale Measurements
}

\author{
MATHIEU SUZANNE, MICHAEL DELICHATSIOS, and JIANPING ZHANG \\ FireSERT, Research Institute of Built Environment \\ University of Ulster at Jordanstown \\ Newtownabbey, BT37 0QB, Northern Ireland
}

\begin{abstract}
The limited oxygen index (LOI) test is a small-scale test for characterising the flammability tendency of materials ignited with a small candle-like diffusion flame. It involves determination of the minimum oxygen volume concentration in an oxygen/nitrogen mixture required to just support the downward burning on a vertically mounted test specimen. Over the last decades, much effort has been devoted to developing correlations between the LOI of a material with its chemical or physical properties. However these correlations were deduced based mainly on empirical fitting, and as a result they cannot be related to the fundamental properties of the material. In this work, we present a novel approach based on simple extinction theory to predict the LOI of materials using their flammability properties measured in smallscale tests (i.e. TGA, DSC and the cone calorimeter). The present method is first applied to five polymers and the predicted LOI values in general agree with the measurements. Subsequently, the model is extended to examine the effects of the initial sample temperature and external heat flux on the LOI of a PMMA, PS and POM in reasonable agreement with the experimental data.
\end{abstract}

KEYWORDS: extinction, flammability, heat transfer, limiting oxygen index.

\section{NOMENCLATURE LISTING}

\begin{tabular}{|c|c|c|c|}
\hline$c$ & sample specific heat $\left(\mathrm{kJ} \cdot \mathrm{kg}^{-1} \cdot \mathrm{K}^{-1}\right)$ & Greek & \\
\hline$c_{p}$ & gas specific heat $\left(\mathrm{kJ} \cdot \mathrm{kg}^{-1} \cdot \mathrm{K}^{-1}\right)$ & $\alpha$ & $\begin{array}{l}\text { normalized temperature difference } \\
\text { between wall and ambient }\end{array}$ \\
\hline$h_{c}$ & $\begin{array}{l}\text { effective heat transfer coefficient at zero } \\
\text { mass flux rate }\left(\mathrm{kW} \cdot \mathrm{m}^{-2} \cdot \mathrm{K}^{-1}\right)\end{array}$ & $v$ & $\begin{array}{l}\text { stoichiometric coefficient in combustion } \\
\text { reaction }\end{array}$ \\
\hline$\Delta H_{c}$ & heat of combustion $\left(\mathrm{kJ} \cdot \mathrm{kg}^{-1}\right)$ & $\rho$ & density $\left(\mathrm{kg} \cdot \mathrm{m}^{-3}\right)$ \\
\hline$\Delta H_{p}$ & total heat of gasification $\left(\mathrm{kJ} \cdot \mathrm{kg}^{-1}\right)$ & $\tau_{c h}$ & chemical time \\
\hline$M$ & molecular weight $\left(\mathrm{g} \cdot \mathrm{mol}^{-1}\right)$ & $\tau_{f}$ & flow time \\
\hline$\dot{m}^{\prime \prime}$ & mass pyrolysis rate per unit area $\left(\mathrm{kg} \cdot \mathrm{m}^{-2} \cdot \mathrm{s}^{-1}\right)$ & $\sigma$ & Stefan-Boltzmann constant $\left(\mathrm{kW} \cdot \mathrm{m}^{-2} \cdot \mathrm{K}^{-4}\right)$ \\
\hline$\dot{q}_{c}^{\prime \prime}$ & convective heat flux $\left(\mathrm{kW} \cdot \mathrm{m}^{-2}\right)$ & $\chi_{s}$ & normalized mass flux at the wall \\
\hline$\dot{q}_{e}^{\prime \prime}$ & external heat flux $\left(\mathrm{kW} \cdot \mathrm{m}^{-2}\right)$ & subscrip & \\
\hline$\dot{q}_{r r}^{\prime \prime}$ & $\begin{array}{l}\text { surface reradiative heat flux (critical heat } \\
\text { flux) }\left(\mathrm{kW} \cdot \mathrm{m}^{-2}\right)\end{array}$ & $a$ & activation \\
\hline$T$ & temperature $(\mathrm{K})$ & ext & extinction \\
\hline$T_{0}$ & initial material temperature $(\mathrm{K})$ & $f$ & fuel \\
\hline$Y_{F T}$ & fuel concentration in the supplied fuel & $f l$ & flame \\
\hline$\tilde{Y}_{0 \infty}$ & ambient oxygen mass fraction & $o$ & oxygen \\
\hline$Y_{0 \infty}$ & normalized oxygen concentration at infinity & $w$ & wall \\
\hline
\end{tabular}

\section{INTRODUCTION}

The limiting oxygen index (LOI) test is commonly used to assess the relative flammability of a material by studying its tendency to sustain a flame by varying the oxygen concentration in a small enclosure. First introduced more than forty years ago by Fenimore and Martin [1], the LOI measurement is now subject to different national or international standards [2,3]. The LOI corresponds to the minimum volume 
concentration of oxygen in an oxygen/nitrogen mixture required to just support the downward burning on a vertically mounted test specimen. The LOI can be expressed as a function of the oxygen and nitrogen volume concentrations as:

$$
L O I=100 \times \frac{\left[O_{2}\right]}{\left[O_{2}\right]+\left[N_{2}\right]}
$$

The LOI is measured for a sample (with typical length between 70 and $150 \mathrm{~mm}, 6.5 \mathrm{~mm}$ in width and $3 \mathrm{~mm}$ in thickness) placed in the centre of a glass chimney where the oxygen/nitrogen gas mixture circulates upward. After a $30 \mathrm{~s}$ purge of the chimney with the mixture gas, the top of the specimen is ignited using a diffusion pilot flame and the combustion of the sample is observed until flame extinguishes. The criterion used to assess the sustainability of the downward burning in the controlled atmosphere is either a $50 \mathrm{~mm}$ burning length over the sample or flaming combustion maintained for $180 \mathrm{~s}$ after the ignition.

The two clear advantages of LOI tests are: a) it is a well reproducible test which only requires small size samples and b) it provides a single figure regarding the flammability of a material and, consequently, it is deemed useful in ranking the flammability of materials. Because of these advantages, the LOI is widely used to investigate the flammability of fire-retarded materials. In these studies, empirical correlations have been developed between the LOI values and parameters related to the chemistry of the materials such as the polymer residue [4], the char yield ratio [5] and the flame-retardant concentration [6-8]or to the physical properties (such as the glass transition temperature $[9,10]$ ). As these correlations are determined based on curve fitting, they are not related to the fundamental flammability properties, which are required in order to predict the burning behaviours of these materials in intermediate and large-scale tests.

In this work, a novel approach is presented to explain quantitatively and predict the LOI of materials using their flammability properties measured in small-scale tests (i.e. TGA, DSC and cone calorimeter). The present method is based on simple flame extinction theory [14] by noting that the critical mass flux is similar for ignition and extinction. The extinction results in [14] were developed for a counter flow situation of the oxidizer flowing against the solid material but they can be applied for other flow geometries if an effective heat transfer coefficient is identified. The present method is firstly applied to five polymers, for which LOI values have been reported in the literature [21-42]. Generally, the predictions agree with the measurements. It is, however, found that the predicted LOI values are sensitive to the effective convective heat transfer coefficient, for which a sensitivity study is carried out. Subsequently, the model is used to examine the effects of the initial sample temperature and external heat flux on the LOI of PMMA, PS and POM [49].

\section{PREDICTION OF THE LIMITING OXYGEN INDEX}

\section{Equations Governing the Flame Extinction in the Limiting Oxygen Index Test}

Burning of a solid material is a process involving strong interaction of pyrolysing gas burning and solid degradation. The combustible volatile generated from the degradation of the solid ignites and the flame provides additional heat to the solid. In order to fully investigate this process, it is desirable that the gas and solid phases are taken into account simultaneously. However, such a complete study would require extensive computational overheads. In order to simplify this complex process and develop a practical method, flame extinction near the sample surface in the LOI test is studied by separating the gas phase phenomenon from the solid phase one i.e. gaseous heat transfer and mass balance of the sample are considered separately.

\section{Gas Phase Heat Transfer}

The convective heat flux from the flame to the sample was measured in [11,12] as a function of the mass supply rate of the fuel in a porous burner. It was observed experimentally that when the mass supply rate decreases, the convective heat flux from the flame increases owing to reduced blowing until it reaches a maximum value. With a further decrease in the mass flux, the convective heat flux decreases as the flame approaches the surface because of quenching of the chemical reaction. As an analogy to the combustion of a solid material, the mass supply of the fuel in the porous burner may be related to the rate of mass 
pyrolysis and the mass flux corresponding to the maximum of the convective heat flux is the critical mass flux at which extinction occurs [13]. For a solid material, when the rate of mass pyrolysis becomes lower than the critical mass flux, the energy balance at the surface of the material does not allow to sustain a flame and extinction conditions are reached.

In [14-16], the convective heat flux to the surface was derived as:

$$
\dot{q}_{c}^{\prime \prime}=\frac{h_{c}}{c_{p}} \Delta H_{c}\left(Y_{o \infty}-\alpha\right) \exp \left(-\frac{\chi_{s}^{2}}{2}\right)
$$

where $h_{c}$ is the convective heat transfer coefficient to the surface at zero mass flux, $c_{p}$ the specific heat, $Y_{o \infty}$ the normalized oxygen concentration at infinity, $\chi_{s}$ the normalized mass flux at the wall and $\alpha$ the normalized temperature difference between wall and ambient temperature. The expressions of $Y_{o \infty}, \chi_{S}$ and $\alpha$ are given as [14]:

$$
Y_{0 \infty}=\frac{\tilde{Y}_{0 \infty}}{\left(\frac{v_{0} M_{0}}{v_{f} M_{f}}\right)}, \chi_{s}=\frac{\dot{m} c_{p}}{h_{c}}, \alpha=\frac{T_{w}-T_{\infty}}{\frac{\Delta H_{c}}{c_{p}}}
$$

Equation 2 was derived for burning in a counter flow of oxidizer against a solid material and can be generalized for other flow situations for appropriate values of the convective heat transfer coefficient. Equation 2 includes the reduction of the heat flux through the exponential term as the mass blowing at the surface increases.

The above derivation is supported by Fig. 1, which shows the calculated flame heat flux feedback to the surface versus the normalized mass flux at the wall for both infinitely fast kinetics and when this heat flux is maximum and also by asymptotic analyses for plane counter-flow flame situation carried elsewhere [1316]. The approximate expression of the convective heat flux in Eq. 2 is strictly valid for infinite kinetics but is nearly true at extinction.

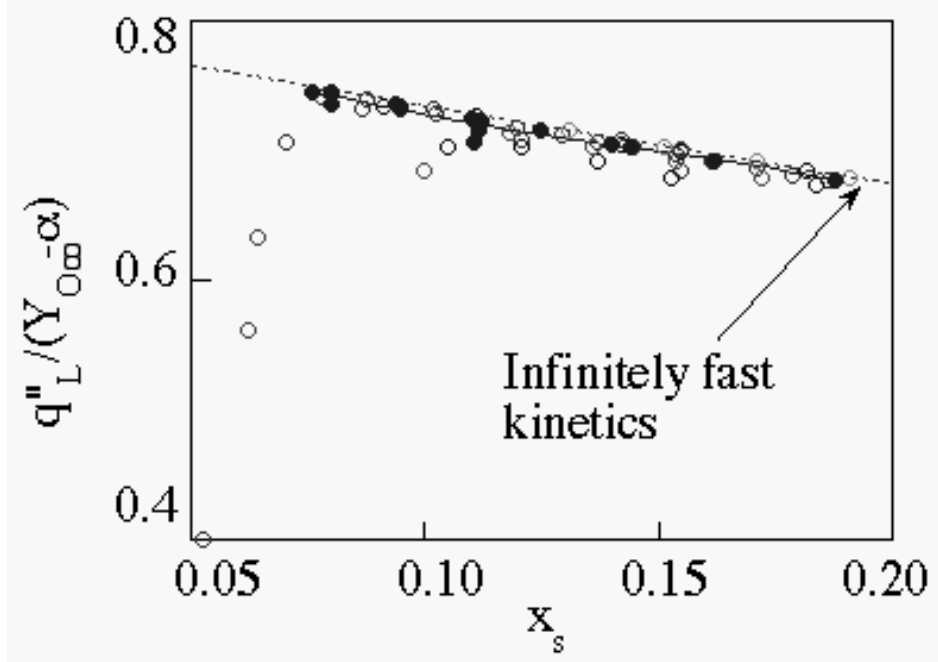

Fig. 1. Calculated flame heat flux feedback to the surface versus the normalized mass flux at the wall for infinitely fast kinetics (dotted line) and when this heat flux is maximum (solid symbols).

The critical mass flux at extinction $\dot{m}_{\text {ext }}^{\prime \prime}$ can be expressed as a function of the flow time $\tau_{f}$ (characteristic of the strain rate near the flame), the chemical time $\tau_{c h}$ (excluding any flow effects), the activation temperature 
$T_{a}$ and the flame temperature $T_{f l} \cdot Y_{O \infty}$ and $Y_{F T}$ are respectively the normalized oxygen concentration at infinity and fuel concentration in the supplied fuel.

$$
\frac{\dot{m}_{e x t}^{\prime \prime} c_{p}}{h_{c}}\left(Y_{F T}+Y_{O \infty}\right)=\text { function of }\left(\frac{\tau_{f}}{\tau_{c h}} e^{-\frac{T a}{T f l}}\right)
$$

When the modified Damköhler number, $\frac{\tau_{f}}{\tau_{c h}} e^{-\frac{T a}{T f l}}$, is sufficiently high, asymptotic and numerical results in [14-16] show that the dimensionless critical fuel flux is constant, i.e.:

$$
\frac{\dot{m}_{e x t}^{\prime \prime} c_{p}}{h_{c}}\left(Y_{F T}+Y_{O \infty}\right)=\text { constant }
$$

The fuel concentration in the supplied fuel is supposed constant and equal to 1 . The normalized oxygen concentration at infinity (see Eq. 3) is relatively small compared to the fuel concentration in the supplied fuel and is neglected in Eq. 5. According to these simplifications, Eq. 5 becomes:

$$
\frac{\dot{m}_{e x t}^{\prime \prime} c_{p}}{h_{c}}=\chi_{\mathrm{s}}=\text { constant }
$$

The constant in Eq. 6 varies with materials. For the present applications, the chemical effects of the Damköhler number are ignored since oxygen concentrations in LOI tests are usually high.

\section{Solid Phase}

For a pyrolysing and burning solid, the convective heat flux can be determined by considering the energy balance at the surface of the burning material at steady state:

$$
\dot{q}_{c}^{\prime \prime}=\dot{m} \Delta H_{p}+\dot{q}_{r r}^{\prime \prime}-\dot{q}_{e}
$$

where $\dot{m}^{\prime \prime}$ is the mass pyrolysis rate per unit area, $\Delta H_{p}$ the total heat of pyrolysis consisting of both the latent heat and sensible heat needed to heat up the fuel from its initial temperature to the pyrolysis solid temperature, $\dot{q}_{r r}^{\prime \prime}$ the re-radiative heat flux, and $\dot{q}_{e}^{\prime \prime}$ the external heat flux. It should be noted that, near extinction, radiative heat flux from the flames is negligible because the mass flux of the fuel is low.

\section{Determination of LOI}

From Eqs. 2 and 7, one obtains:

$$
\frac{h_{c}}{c_{p}} \Delta H_{c}\left(Y_{o \infty}-\alpha\right) \exp \left(-\frac{\chi_{s}^{2}}{2}\right)=\dot{m}^{\prime \prime} \Delta H_{p}+\dot{q}_{r r}^{\prime \prime}-\dot{q}_{e}
$$

Equation 8 can be re-arranged with the use of Eq. 3 as:

$$
\left(Y_{o \infty}-\alpha\right) \exp \left(-\frac{\chi_{s}^{2}}{2}\right)=\chi_{s} \frac{\Delta H_{p}}{\Delta H_{c}}+\frac{\left(\dot{q}_{r r}^{\prime \prime}-\dot{q}_{e}^{\prime \prime}\right) c_{p}}{h_{c} \Delta H_{c}}
$$


where $Y_{0 \infty}=\frac{\tilde{Y}_{0 \infty}}{\left(\frac{v_{0} M_{0}}{v_{f} M_{f}}\right)} \cdot \tilde{Y}_{0 \infty}$, the critical oxygen concentration at extinction, can be related to the LOI by:

$L O I=100 \times \frac{\tilde{Y}_{0 \infty} \rho_{N_{2}}}{\tilde{Y}_{0 \infty} \rho_{N_{2}}+\left(1-\tilde{Y}_{0 \infty}\right) \rho_{O_{2}}}$

Equation 9 shows that that the LOI depends on the critical mass pyrolysis rate at extinction, the normalized temperature difference $\alpha$, the ratio $\Delta H_{p} / \Delta H_{c}$, the normalized mass flux $\chi_{s}$ and the ratio $\left(\dot{q}_{r r}^{\prime \prime}-\dot{q}_{e}^{\prime \prime}\right) c_{p} / h_{c} \Delta H_{c}$. These two last quantities depend on the effective heat transfer coefficient $h_{c}$. This dependence on the heat transfer coefficient explains the variation of the LOI with the sample dimensions [17], the gas velocity [18] or the equipment dimensions [19,20] and the difficulty to relate LOI to intermediate- and large-scale fires.

Note that the flammability properties of materials (i.e. the heat of combustion, the heat of pyrolysis, the specific heat, the critical mass flux and the critical heat flux) can be determined in small-scale tests (i.e. TGA, DSC and the cone calorimeter).

\section{Graphical Approximation of the Limiting Oxygen Index}

For direct illustration, a graphical representation is used to determine the LOI from Eqs. 6 and 9. As shown in Fig. 2, the steps in determining the LOI values are:

1. First, we plot the LHS of Eq. 9 as a function of $\chi_{s}$ (see Eq. 3) at different oxygen concentrations. This term, which is proportional to the convective heat flux, increases with the ambient oxygen concentration as expected.

2. Next, we plot the RHS of Eq. 9 as a function of $\chi_{s}$ (see Eq. 3) on the same graph. In order to determine whether a flame can exist and sustain itself, there must be an interception between the RHS and LHS of Eq. 9. An interception between these two curves leads to a stationary solution which corresponds to stable burning conditions while no interception indicates un-sustainability conditions, which occur when the heat loss at the fuel surface is too high in comparison to the convective heat flux provided by the gaseous phase.

3. The critical mass loss flux for extinction depends on experimental conditions and the effective heat transfer coefficient. However as noted earlier in Eq. 6, the normalized mass flux at extinction is considered constant. Thus, if the critical mass flux at extinction is known, we can determine the critical oxygen concentration by locating the interception of the RHS of Eq. 9, the LHS of Eq. 9 and the normalized mass flux at extinction (Eq. 6). This oxygen mass fraction can then be used to calculate the LOI using Eq. 10. 


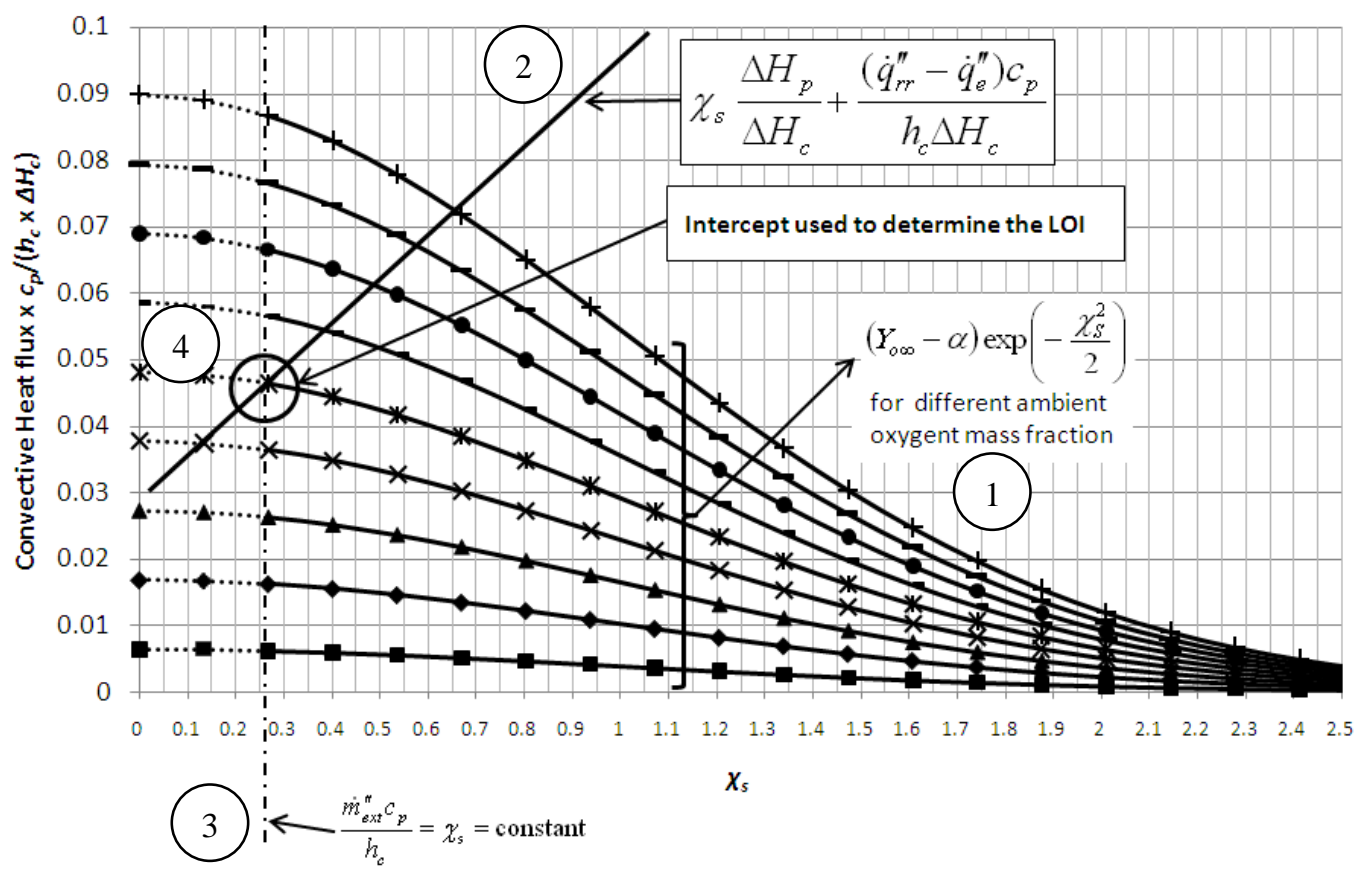

Fig. 2. Graphical approximation of the LOI

\section{Application of the Method to Polymers}

\section{Experimental Values of LOI}

In this work, five polymers were chosen to assess the determination of LOI using the present model, namely Polypropylene (PP), Polymethylmethacrylate (PMMA), Polyethylene (PE), Polystyrene (PS) and Polyoxymethylene (POM). These materials have been subject to a number of LOI studies [21-42] and the results are summarised in Table 1. As the values from different studies are similar, the average values of the LOI values reported are used to compare with the prediction.

Table 1. Values of LOI found in the literature for PP, PMMA, PE, PS and POM.

\begin{tabular}{|c|c|c|c|c|c|c|c|c|c|}
\hline \multicolumn{2}{|c|}{ POM } & \multicolumn{2}{c|}{ PMMA } & \multicolumn{2}{c|}{ PP } & \multicolumn{2}{c|}{ PS } & \multicolumn{2}{c|}{ PE } \\
\hline LOI & Reference & LOI & Reference & \multicolumn{1}{c|}{ LOI } & Reference & LOI & Reference & LOI & Reference \\
\hline 16 & {$[41]$} & 18 & {$[9]$} & 17 & {$[21]$} & 18.8 & {$[37]$} & 17.4 & {$[32]$} \\
15 & {$[42]$} & 17.5 & {$[26]$} & 17.5 & {$[22]$} & 17.9 & {$[38]$} & 17.8 & {$[33]$} \\
15 & {$[32]$} & 14 & {$[26]$} & 18.3 & {$[23]$} & 18 & {$[39]$} & $19.2(\mathrm{HD})$ & {$[34]$} \\
& & 16.9 & {$[28]$} & 18 & {$[24]$} & 18.3 & {$[40]$} & $20.2(\mathrm{LD})$ & {$[35]$} \\
& & 17.2 & {$[29]$} & 17 & {$[25]$} & 17.8 & {$[32]$} & 17.3 & {$[36]$} \\
& & 17.8 & {$[30]$} & & & & & & \\
& & 17.3 & {$[31]$} & \multicolumn{1}{|c|}{} & & & & & \\
\hline 15.3 & Average & 17.0 & Average & 17.6 & Average & 18.2 & Average & 18.4 & Average \\
+0.7 & & +1 & & +0.7 & & +0.6 & & +1.8 & \\
-0.3 & & -3 & & -0.6 & & -0.6 & & -1.1 & \\
\hline
\end{tabular}

Best flammability properties according to the LOI test

\section{Model Parameters}

The properties and parameters used in the predictions are summarised in Table 2. The majority of these parameters can be found from the chemical structure of the materiel except the wall (surface) temperature and the total heat of pyrolysis. For polymers, the temperature at the surface during pyrolysis remains nearly constant (the so-called pyrolysis temperature), and thus the pyrolysis temperature of the polymers were 
used in the calculations. The pyrolysis temperatures and total heat of pyrolysis were taken from [50] based on differential scanning calorimetry (DSC) measurements. The other data (heat of combustion, surface reradiative heat flux, etc.) were taken from [43].

Table 2. Summary of the parameters used to determine the LOI of the materials studied in this work.

\begin{tabular}{|c|c|c|c|c|c|c|}
\hline Quantities & $\mathbf{P P}$ & PMMA & $\mathbf{P E}$ & PS & POM & Units \\
\hline Chemical formulation & $\left(\mathrm{C}_{3} \mathrm{H}_{6}\right)_{\mathrm{n}}$ & $\left(\mathrm{C}_{5} \mathrm{H}_{8} \mathrm{O}_{2}\right)_{\mathrm{n}}$ & $\left(\mathrm{C}_{2} \mathrm{H}_{4}\right)_{\mathrm{n}}$ & $\left(\mathrm{C}_{8} \mathrm{H}_{8}\right)_{\mathrm{n}}$ & $\left(\mathrm{CH}_{2} \mathrm{O}\right)_{\mathrm{n}}$ & \\
\hline$c_{p}$ (Air) & 1.005 & 1.005 & 1.005 & 1.005 & 1.005 & 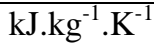 \\
\hline$\Delta H_{c}$ & 38600 & 24890 & 38400 & 27000 & 14400 & $\mathrm{~kJ}^{\mathrm{kg}}{ }^{-1}$ \\
\hline$v_{f}$ & 1 & 1 & 1 & 1 & 1 & \\
\hline$v_{o}$ & 4.5 & 6 & 3 & 10 & 1 & \\
\hline$M_{f}$ & 42 & 100 & 28 & 104 & 30 & g.mol ${ }^{-1}$ \\
\hline$M_{o}$ & 32 & 32 & 32 & 32 & 32 & g. $\mathrm{mol}^{-1}$ \\
\hline$T_{w}$ & 720 & 639 & 751 & 700 & 642 & $\mathrm{~K}$ \\
\hline$T_{\infty}$ & 293 & 293 & 293 & 293 & 293 & $\mathrm{~K}$ \\
\hline$\dot{q}_{r r}^{\prime \prime}$ & 15 & 11 & 15 & 13 & 13 & $\mathrm{~kW} \cdot \mathrm{m}^{-2}$ \\
\hline$\Delta H_{p}$ & 2540 & 1600 & 2510 & 1800 & 3370 & $\mathrm{~kJ} . \mathrm{kg}^{-1}$ \\
\hline$T_{0}$ & 293 & 293 & 293 & 293 & 293 & $\mathrm{~K}$ \\
\hline
\end{tabular}

In addition to the parameters shown in Table 2, the other two important parameters are the critical mass flux and the convective heat transfer coefficient. As there are no data available for the critical mass loss rate at extinction, the critical mass loss rate for ignition is used. The critical mass loss rate for flame extinction is similar to the critical mass loss rate for ignition, if the critical mass loss rate for ignition is exactly measured when the sustained flame is just being established [43].

The critical mass pyrolysis rates were reported in [44] and [45], using two different apparatus: Tewarson [44] used the ASTM E 2058 fire propagation apparatus whereas Thomson et al. [45] used a customized apparatus developed at the University of Edinburgh. There is a noticeable difference in the values from these studies. For example, in [44] a critical mass flux of $2.7 \mathrm{~g} \cdot \mathrm{m}^{-2} \cdot \mathrm{s}^{-1}$ whereas $1.1 \mathrm{~g} \cdot \mathrm{m}^{-2} \cdot \mathrm{s}^{-1}$ was measured in [45] for PP. Such a difference may be explained by boundary layer conditions at the surface of the sample which differ from one apparatus to the other and especially the conditions governing the convective heat transfer [45]. Tewarson later suggested that the critical mass loss rate for ignition may have been measured when the sustained flame is just being established in ASTM E 2058 test while just before established in the other test [43]. In the present study, the critical mass pyrolysis rates measured by Thomson et al. [45] are used because they also report the effective heat transfer coefficient related to their measurements, which allows the determination of the normalized mass flux constant at extinction using Eq. 6. Values of critical mass loss rate and normalized mass flux at extinction used in the present study are listed in Table 3.

Table 3. Critical mass loss rate and normalized mass flux at extinction.

\begin{tabular}{|l|c|c|}
\hline Material & Critical mass loss rate [45] & $\chi_{s}$ \\
\hline Polypropylene & $1.1 \mathrm{~g} / \mathrm{m}^{2} \cdot \mathrm{s}$ & 0.111 \\
\hline Polymethylmethacrylate & $1.9 \mathrm{~g} / \mathrm{m}^{2} \cdot \mathrm{s}$ & 0.191 \\
\hline Polyethylene & $1.3 \mathrm{~g} / \mathrm{m}^{2} \cdot \mathrm{s}$ & 0.131 \\
\hline Polystyrene & $0.80 \mathrm{~g} / \mathrm{m}^{2} \cdot \mathrm{s}$ & 0.080 \\
\hline Polyoxymethylene & $1.7 \mathrm{~g} / \mathrm{m}^{2} \cdot \mathrm{s}$ & 0.171 \\
\hline
\end{tabular}

The effective heat transfer coefficient is the most difficult parameter to determine accurately, because it depends on a number of factors, such as the orientation of the sample, the flow around the surface, the sample size, the material temperature, etc. This is highlighted by the fact that different researchers reported a wide range of values even for the same test. For example, for the cone calorimeter tests, a value of $8.0 \mathrm{~W} \cdot \mathrm{m}^{-2} \cdot \mathrm{K}^{-1}$ has been reported for a vertical sample in natural turbulent convection, $13.5 \mathrm{~W} \cdot \mathrm{m}^{-2} \cdot \mathrm{K}^{-1}$ for a horizontal orientation and up to $15 \mathrm{~W} \cdot \mathrm{m}^{-2} \cdot \mathrm{K}^{-1}$ for wood in vertical orientation [46], between 7 and $15 \mathrm{~W} \cdot \mathrm{m}^{-2} \cdot \mathrm{K}^{-1}$ in [47], $13.5 \mathrm{~W} \cdot \mathrm{m}^{-2} \cdot \mathrm{K}^{-1}$ (without the edge frame) and $16 \mathrm{~W} \cdot \mathrm{m}^{-2} \cdot \mathrm{K}^{-1}$ (with the edge frame) in [48]. As no measurements have been carried out for the LOI test and a theoretical value is hardly 
determinable as the film temperature is not well characterized in that flaming configuration, we used different values (from 5 to $15 \mathrm{~W} \cdot \mathrm{m}^{-2} \cdot \mathrm{K}^{-1}$ ) of the heat transfer coefficient in order to assess the effects of $h_{c}$ on the LOI.

\section{Results and Discussions}

The predicted LOI are plotted in Fig. 3 as a function of the effective heat transfer coefficient for the five materials. The predicted LOI decreases with an increase of the convective heat transfer coefficient. It can be seen that the predicted LOI is very sensitive to the effective heat transfer coefficient especially at lower values of $h_{c}$. The optimal values of $h_{c}$ that yield the best agreement with the experimental data are $10 \mathrm{~W} \cdot \mathrm{m}^{-2} \cdot \mathrm{K}^{-1}$ for PP, POM and PE, $11 \mathrm{~W} \cdot \mathrm{m}^{-2} \cdot \mathrm{K}^{-1}$ for PS and $7 \mathrm{~W} \cdot \mathrm{m}^{-2} \cdot \mathrm{K}^{-1}$ for PMMA. In [45], a convective heat transfer coefficient of $10 \mathrm{~W} \cdot \mathrm{m}^{-2} \cdot \mathrm{K}^{-1}$ was reported. This value is close to the ones obtained from Fig. 3 by comparing the predicted and measured LOI values. Clearly, it would be desirable to measure more precisely the heat transfer coefficient $h_{c}$ for future applications of the present method.

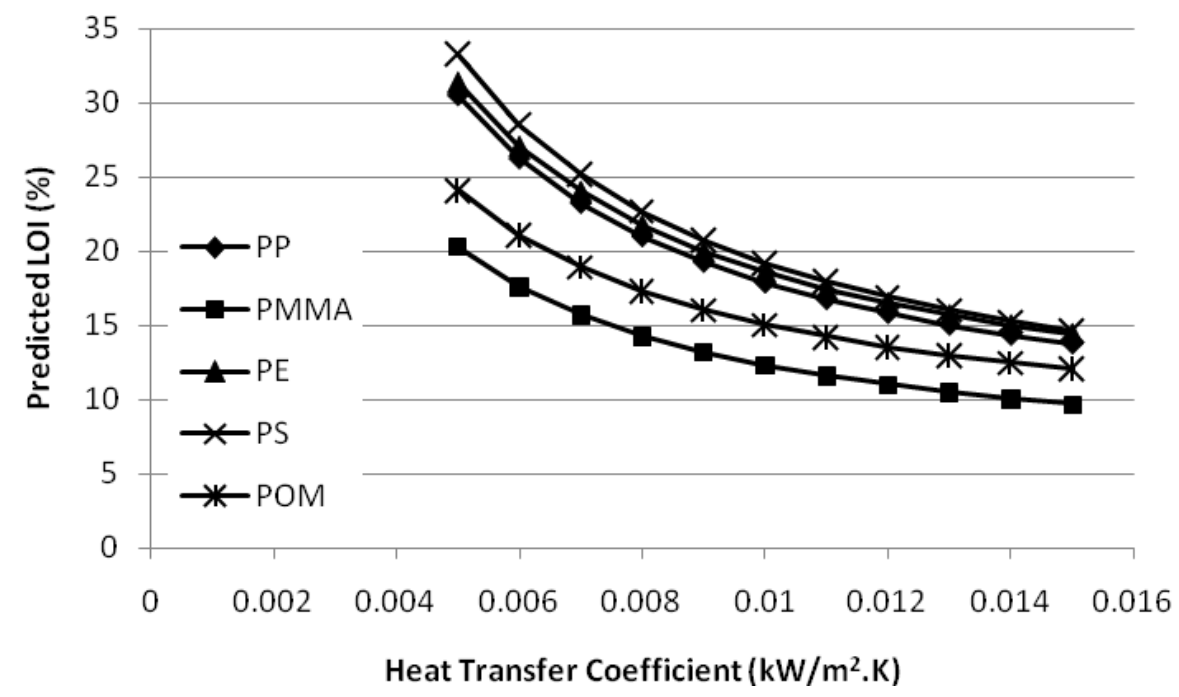

Fig. 3. Approximation of the LOI of PMMA, PP, POM, PE and PS as a function of the effective heat transfer coefficient.

\section{DEPENDENCE OF LOI ON THE SAMPLE TEMPERATURE AND ON THE EXTERNAL RADIANT HEAT FLUX}

Zubanov and Gibov [49] used a modified apparatus to study the LOI of polymethylmethacrylate (PMMA), polystyrene (PS) and polyoxymethylene (POM). They studied the effects of the initial sample temperature and external heat flux and found that the LOI decreases with an increase of both. First we note that this behaviour is consistent with our predictions in Eqs. 8 and 9. In this section, we apply the present method to predict the tests reported in Ref. [49]: the influence of external radiant heat flux on LOI for PMMA and effect of the initial temperature of the sample on LOI for PMMA, PS and POM. The model parameters remain the same as those listed in Table 2, except for the wall temperature. In Ref. [49], the surface temperature was measured to be around 650K for PMMA and 700K for PS, independent of the initial sample temperature. This temperature for PMMA is slightly higher than those reported in the literature.

Figure 4 shows a comparison of the predicted and measured LOI at different sample initial temperatures divided by the LOI value at $298 \mathrm{~K}$. The model appears to underestimate the decrease of the LOI with an increase in the initial sample temperature. From Eq. 9, we note that the change in the initial sample temperature only has effect on the solid phase by modifying the total heat of pyrolysis $\Delta H_{p}$. As a consequence this affects the slope of the right hand side of the Eq. 9 plotted as a function of the normalized mass flux and modifies the intercept with the left hand side of the Eq. 9 plotted as a function of the normalized mass flux. 
For the PMMA, PS and POM, an increase of the initial sample temperature from 300 to $500 \mathrm{~K}$ decreases the total heat of pyrolysis of respectively around 26,21 and $13 \%$. It was thought that the difference in measured and predicted LOI could be due to the use of a constant specific heat for the materials. However, the use of temperature-dependent specific heat does not improve noticeably the prediction. In addition, the extent of the change in the LOI with an increase of the initial sample temperature appears characteristic to each polymer. This indicates that the LOI of a material depends strongly on its thermodynamic and thermal properties including its heat of pyrolysis.

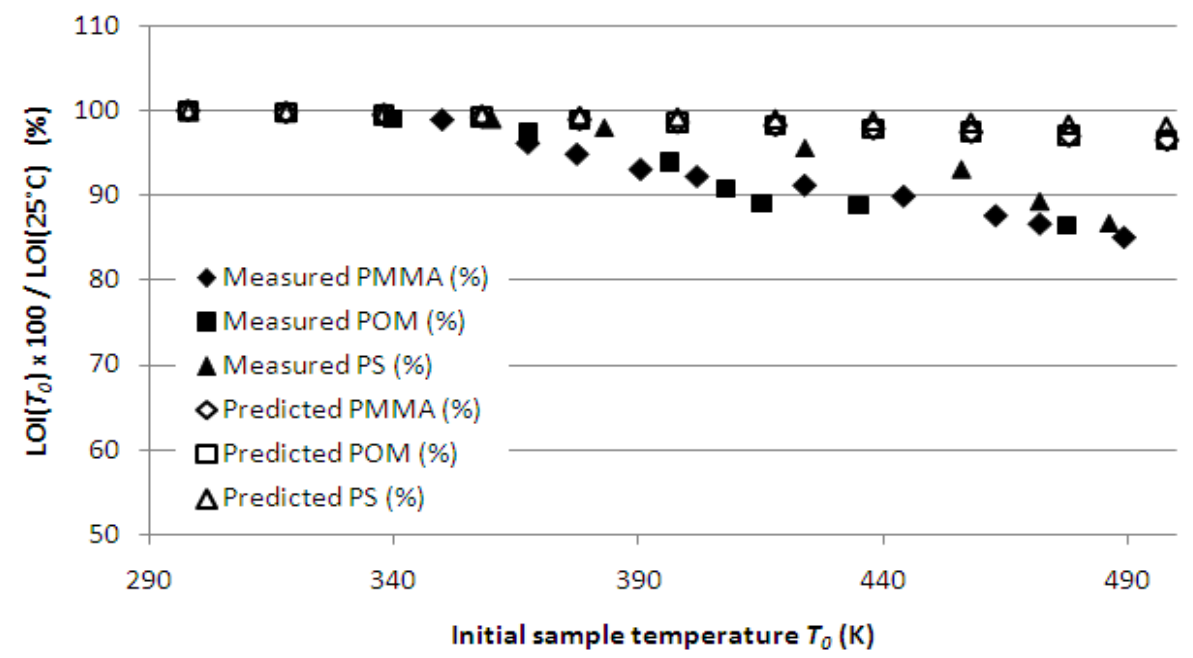

Fig. 4. Effect of the initial sample temperature on the measured and predicted LOI for PMMA, POM and PS.

Fig. 5 compares the predicted LOI with the measurements at different external heat fluxes. There is a significant decrease of the LOI with the external heat flux from both the prediction and experimental data. The prediction is in good agreement with the experimental data at lower heat fluxes (below $5 \mathrm{~kW} \cdot \mathrm{m}^{-2}$ ). With a further increase in the external heat flux, the prediction starts to deviate from the experimental data. One possible explanation is that with an increase of the external heat flux in the experiment, the surface temperature may increase, which will then result in an increase of the radiation losses on the surface. The change of the wall temperature with external heat flux was not accounted for in the model because there were no experimental data available. In the calculations, the wall temperature was assumed to be constant (the pyrolysis temperature).

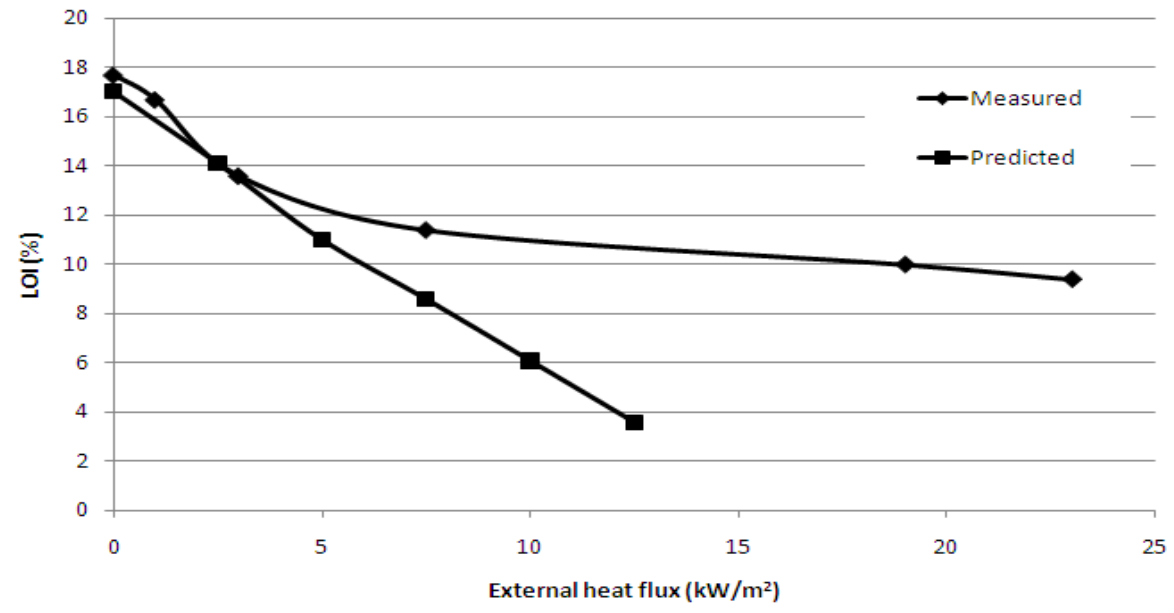

Fig. 5. Influence of the external radiant heat flux upon the measured and predicted LOI for PMMA. 


\section{CONCLUSIONS}

A novel method to predict the LOI was presented in this paper. It is based on a simplified flame extinction theory and differs from existing empirical correlations. The present method incorporates the flammability properties of the material (i.e. the heat of combustion, the heat of pyrolysis, the specific heat, the critical mass flux and the critical heat flux) that can be measured in small-scale tests (TGA, DSC, and cone calorimeter) as shown by Eqs. 8 and/or 9 and illustrated in Fig. 2. The method was first applied to five materials (Polypropylene, Polymethylmethacrylate, Polyethylene, Polystyrene and Polyoxymethylene) and subsequently extended to study the effects of the initial sample temperature and external heat flux on the LOI of PMMA, PS and POM.

The predicted LOI for the five materials are close to the values reported in the literature. However, the results show that there is a strong dependence of the predicted LOI on the effective heat transfer coefficient, which may vary with experimental conditions. The optimal values of effective heat transfer coefficient obtained from comparing the predicted and experimental LOI are close to those reported in [45].

The changes in the predicted LOI with the initial sample temperature and the external heat flux were also studied and compared to measurements for a PMMA, PS and POM. The model predicts correctly the trends of the experimental data. However, the decrease in the LOI with an increase of the temperature was underestimated (see Fig. 4). The decrease in the LOI with an increase of the external heat flux was reproduced for low heat fluxes (less than $5 \mathrm{~kW} \cdot \mathrm{m}^{-2}$ ) but overestimated with a further increase in the external heat flux. These differences highlight the difficulties in predicting the LOI because not all the material properties are known or can be determined accurately. Nevertheless, this work provides a simple but useful way to explain quantitatively and predict the LOI of a material.

In order to demonstrate the applicability of the LOI prediction, the method was evaluated for five polymers using material properties reported in the literature. However, this method can also be easily used to predict the LOI of other materials as long as their flammability properties can be measured. For example, for polymers with additives, the influence of additives in the polymers can be directly taken into account in the method through the modifications of the flammability properties measured in small-scale tests.

Although the present method is developed to predict the LOI values, it can also be used to estimate the critical mass flux at extinction using the measured LOI values. However, both applications require that the convective heat transfer coefficient in the LOI apparatus be determined accurately.

\section{REFERENCES}

[1] Fenimore, C., and Martin, F., (1966) Flammability of Polymers, Combustion and Flame 10: 135139, http://dx.doi.org/10.1016/0010-2180(66)90059-9

[2] ISO 4589, Plastics -- Determination of Burning Behaviour by Oxygen Index, Plastic Test Standard, International Organization for Standardization, Geneva, 1996

[3] ASTM D2863, Standard Method for Measuring the Minimum Oxygen Concentration to Support Candle-like Combustion of Plastics (Oxygen Index), ASTM International, West Conshohocken, PA, 2009.

[4] Van Krevelen, D., (1975) Some Basic Aspect of Flame Resistance of Polymeric Materials, Polymer 16(8): 615-620, http://dx.doi.org/10.1016/0032-3861(75)90157-3

[5] Jeng, R.-J., Shau, S.-M., Lin, J.-J., Su, W.-C., and Chiu, Y.-S.F., (2001) Flame retardant epoxy polymers based on all phosphorus-containing components, European Polymer Journal 38: 683693, http://dx.doi.org/10.1016/S0014-3057(01)00246-4

[6] Kuo, P.-L., Chang, J.-M., and Wang, T.-L., (1997) Flame-Retarding Materials -I. Syntheses and Flame Retarding Property of Alkylphosphate-Type Polyols and Corresponding Polyurethanes, Journal of Applied Polymer Science 69(8): 1635-1643, http://dx.doi.org/10.1002/(SICI)10974628(19980822)69:8<1635::AID-APP17>3.0.CO;2-T

[7] Granzow, A., and Cannelongo, J., (1976) The Effect of Red Phosphorus on the Flammability of Poly(ethylene terephtalate), Journal of Applied Polymer Science 20: 689-701, http://dx.doi.org/10.1002/app.1976.070200311. 
[8] Weil, E., "Additivity, Synergism and Antagonism in Flame Retardancy", Flame Retardant Polymeric Materials (vol.2), Kuryla W., and Papa A. (ed), New York, 1975, p. 103/128.

[9] Laachachi, A., Cochez, M., Ferriol, M., Lopez-Cuesta, J.-M., and Leroy, E., (2005) Influence of $\mathrm{TiO}_{2}$ and $\mathrm{Fe}_{2} \mathrm{O}_{3}$ fillers on the thermal properties of Poly(methyl methacrylate) (PMMA), Materials Letters 59: 36-39, http://dx.doi.org/10.1016/j.matlet.2004.09.014

[10] Laachachi, A., Cochez, M., Ferriol, M., Leroy, E., Lopez-Cuesta, J.-M., and Oget, N., (2004) Influence of $\mathrm{Sb}_{2} \mathrm{O}_{3}$ particles as filler on the thermal stability and flammability properties of poly(methyl methacrylate) (PMMA), Polymer Degradation and Stability 85(1): 641-646, http://dx.doi.org/10.1016/j.polymdegradstab.2004.03.003

[11] Corlett, R. C., (1968) Gas fires with pool-like boundary conditions, Combustion and Flame 12(1): 19-32, http://dx.doi.org/10.1016/0010-2180(68)90005-9

[12] Tsuji, H., (1982) Counterflow diffusion flames, Progress in Energy and Combustion Science 8(2): 93-119, http://dx.doi.org/10.1016/0360-1285(82)90015-6

[13] Delichatsios, M.A. and Delichatsios, M.M., 1997. Critical Mass Pyrolysis Rates for Extinction of Fires Over Solid Materials. Fire Safety Science 5: 153-164. http://dx.doi.org/10.3801/IAFSS.FSS.5-153

[14] Delichatsios, M.A., "Surface Extinction of Flames on Solids: Some Interesting Results", Proceedings of the Combustion Institute, Elsevier Inc, 2007, 31(2): 2749-2756.

[15] Gummalla, M., Vlachos, D., and Delichatsios, M., Conditions for Extinction of Solid Fuel Combustion: I Simple Model, Submitted for Publication in Fire Safety Journal in 2010.

[16] Gummalla, M., Vlachos, D., and Delichatsios, M., Conditions for Extinction of Solid Fuel Combustion: II Detailed Model, Submitted for Publication in Fire Safety Journal in 2010.

[17] Wharton, R., (1981) The Effect of Sample Size on the Burning Behavior of Thermoplastic Materials in the Critical Oxygen Index Test, Fire and Materials 5: 73-76, http://dx.doi.org/10.1002/fam.810050207

[18] Wharton, R., (1983) Comments on the Effect of Gas Velocity on Oxygen Index Measurements, Journal of Fire Sciences 1: 459-464, http://dx.doi.org/10.1177/073490418300100605

[19] Wharton, R., (1981) A Note on the Column Dimensions Permitted by ASTM D2863 for Critical Oxygen Index, Journal of Fire and Flammability 12: 236-239.

[20] Wharton, R., (1984) The Performance of Various Testing Columns in Small-Scale Horizontal Burning Studies, Fire and Materials 8: 177-182, http://dx.doi.org/10.1002/fam.810080402

[21] Yang, D., Hu, Y., Song, L., Nie, S., He, S., and Cai, Y., (2008) Catalyzing Carbonization Function of $\alpha$-ZrP Based Intumescent Fire Retardant Polypropylene Nanocomposites, Polymer Degradation and Stability 93: 2014-2018, http://dx.doi.org/10.1016/j.polymdegradstab.2008.02.012

[22] Li, Y., Li, B., Dai, J., Jia, H., and Gao, S., (2008) Synergistic Effects of Lanthanum Oxide on a Novel Intumescent Flame Retardant Polypropylene System, Polymer Degradation and Stability 93: 9-16, http://dx.doi.org/10.1016/j.polymdegradstab.2007.11.002

[23] Peng, H., Zhou, Q., Wang, D.-Y., Chen, L., and Wang, Y.-Z., (2008) A Novel Charring Agent Containing Caged Bicyclic Phosphate and Its Application in Intumescent Flame Retardant Polypropylene Systems, Journal of Industrial and Engineering Chemistry 14: 589-595, http://dx.doi.org/10.1016/j.jiec.2008.05.011.

[24] Chen, X., Yu, Z.-Z., Liu, W., and Zhang, S., (2009) Synergistic Effect of Decabromodiphenyl Ethane and Montmorillonite on Flame Retardancy of Polypropylene, Polymer Degradation and Stability 94: 1520-1525, http://dx.doi.org/10.1016/j.polymdegradstab.2009.04.031.

[25] Lv, P., Wang, Z., Hu, K., and Fan, W., (2005) Flammability and Thermal Degradation of Flame Retarded Polypropylene Composites Containing Melamine Phosphate and Pentaerythritol 
Derivatives, Polymer Degradation and Stability 90: 523-534, http://dx.doi.org/10.1016/j.polymdegradstab.2005.04.003

[26] Yang, F., and Nelson, G., (2006) Polymer/Silica Nanocomposites Prepared Via Extrusion, Polymer Advanced Technology 17: 320-326, http://dx.doi.org/10.1002/pat.695

[27] Chen, C., Yen, W., Kuan, H., Kuan, C., and Chiang, C., (2010) Preparation, Characterization, and Thermal Stability of Novel PMMA/Expandable Graphite Halogen-Free Flame Retardant Composites, Polymer Composites.

[28] Kiliaris, P., and Papaspyrides, C., (2010) Polymer/Layered Silicate (Clay) Nanocomposites: An Overview of Flame Retardancy, Progress in Polymer Science 35: 902-958, http://dx.doi.org/10.1016/j.progpolymsci.2010.03.001

[29] Ebdon, J., Hunt, B., Joseph, P., Konkel, C., Price, D., Pyrah, K., Hull, T., Milnes, G., Hill, S., Lindsay, C., McCluskey, J., and Robinson, I., (2000) Thermal Degradation and Flame Retardance in Copolymers of Methyl Methacrylate with Diethyl(methacryloyloxymethyl)phosphanate, Polymer Degradation and Stability 70: 425-436, http://dx.doi.org/10.1016/S0141-3910(00)00138$\underline{5}$

[30] Price, D., Pyrah, K., Hull, T., Milnes, G., Ebdon, J., Hunt, B., and Joseph, P., (2002) Flame Retardance of Poly(methyl methacrylate) Modified with Phosphorus-containing Compounds, Polymer Degradation and Stability 77: 227-233, http://dx.doi.org/10.1016/S0141-3910(02)00038$\underline{1}$

[31] Ebdon, J., Price, D., Hunt, B., Joseph, P., Gao, F., Milnes, G. and Cunliffe, L., (2000) Flame Retardance in Some Polystyrenes and Poly(methyl methacrylate)s with Covalently Bound Phosphorus-containing Groups: Initial Screening Experiments and Some Laser Pyrolysis Mechanistic Studies, Polymer Degradation and Stability 69: 267-277, http://dx.doi.org/10.1016/S0141-3910(00)00066-5

[32] Beyler, C., and Hirschler, M., "Thermal Decomposition of Polymers", The SFPE Handbook of Fire Protection Engineering ( ${ }^{\text {rd }}$ ed), National Fire Protection Association, Quincy, MA 02269, 2003, p 1-110/1-131.

[33] Wang, D., Liu, Y., Wang, Y.-Z., Perdomo Artiles, C., Hull, T., and Price, D., (2007) Fire Retardancy of a Reactively Extruded Intumescent Flame Retardant Polyethylene System Enhanced by Metal Chelates, Polymer Degradation and Stability 92: 1592-1598, http://dx.doi.org/10.1016/j.polymdegradstab.2007.04.015

[34] Minkova, L, Peneva, Y., Tashev, E., Filippi, S., Pracella, M., and Magagnini, P., (2009) Thermal Properties and Microhardness of HDPE/Clay Nanocomposites Compatibilized by Different Functionalized Polyethylenes, Polymer Testing 28: 528-533, http://dx.doi.org/10.1016/j.polymertesting.2009.04.001

[35] Shimasaki, C., Watanabe, N., Fukushima, K., Rengakuji, S., Nakamura, Y., Ono, S., Yoshimura, T, Morita, H., Takakura, M., and Shiroishi, A., (1997) Effect of the Fire-Retardant, Melanine, on the Combustion and the Thermal Decomposition of Polyamide-6, Polypropylene and Low-Density Polyethylene, Polymer Degradation and Stability 58: 171-180, http://dx.doi.org/10.1016/S01413910(97)00043-8

[36] Yeh, J., Yang, H., and Huang, S., (1995) Combustion of Polyethylene Filled with Metallic Hydroxides and Crosslinkable Polyethylene, Polymer Degradation and Stability 50: 229-234, http://dx.doi.org/10.1016/0141-3910(95)00171-9

[37] Beach, M., Rondan, N., Froese, R., Gerhart, B., Green, J., Stobby, B., Shmakov, A., Shvartsberg, V., and Korobeinichev O., (2008) Studies of Degradation Enhancement of Polystyrene by Flame Retardant Additives, Polymer Degradation and Stability 93: 1664-1673, http://dx.doi.org/10.1016/j.polymdegradstab.2008.06.010

[38] Price, D., Cunliffe, L., Bullett, K., Hull, T., Milnes, G., Ebdon, J., Hunt, B., and Joseph, P., (2007) Thermal Behaviour of Covalently Bonded Phosphate and Phosphonate Flame Retardant 
Polystyrene Systems, Polymer Degradation and Stability 92: 1101-1114, http://dx.doi.org/10.1016/j.polymdegradstab.2007.02.003

[39] Ebdon, J., Hunt, B., and Joseph, P., (2004) Thermal Degradation and Flammability Characteristics of Some Polystyrenes and Poly(methyl methacrylate)s Chemically Modified with Silicon Containing Groups, Polymer Degradation and Stability 83: 191-185, http://dx.doi.org/10.1016/S0141-3910(03)00261-1

[40] Armitage, P., Ebdon, J., Hunt, B., Jones, M., and Thorpe, F., (1996) Chemical Modification of Polymers to Improve Flame Retardance - I. The Influence of Boron Containing Groups, Polymer Degradation and Stability 54: 387-393, http://dx.doi.org/10.1016/S0141-3910(96)00069-9

[41] Wang, Z., Liu, Y., and Wang, Q., (2010) Flame Retardant Polyoxymethylene with Aluminium Hydroxide/Melamine/Novolac Resin Synergistic System, Polymer Degradation and Stability 95: 945-954, http://dx.doi.org/10.1016/j.polymdegradstab.2010.03.028

[42] Ito, M., and Nagai, K., (2008) Degradation Issues of Polymer Materials Used in Railway Field, Polymer Degradation and Stability 93: 1723-1735, http://dx.doi.org/10.1016/j.polymdegradstab.2008.07.011

[43] Tewarson, A., "Generation of Heat and Chemical Compounds in Fires", The SFPE Handbook of Fire Protection Engineering ( $3^{\text {rd }}$ ed.), National Fire Protection Association, Quincy, MA 02269, 2003, 3/82-3/161.

[44] Tewarson, A., "Experimental Evaluation of Flammability Parameters of Polymeric Materials", Flame Retardant Polymeric Materials, Lewin M., Atlas S., Pearce E. (ed.), Plenum Press, New York, 1982, p. 97/153.

[45] Thomson, H.E. and Drysdale, D.D., 1989. Critical Mass Flowrate at the Firepoint of Plastics. Fire Safety Science 2: 67-76. http://dx.doi.org/10.3801/IAFSS.FSS.2-67

[46] Long, R.T., Torero, J.L., Quintiere, J.G. and Fernandez-Pello, A.C., 2000. Scale and Transport Considerations on Piloted Ignition of PMMA. Fire Safety Science 6: 567-578. http://dx.doi.org/10.3801/IAFSS.FSS.6-567

[47] Zhang, J., and Delichatsios, M., (2009) Determination of the Convective Heat Transfer Coefficient in Three-Dimensional Inverse Heat Conduction Problems, Fire Safety Journal 44: 681-690, http://dx.doi.org/10.1016/j.firesaf.2009.01.004.

[48] Janssens, M., and Gomez, C., "Convective Heat Transfer in the Cone Calorimeter Revisited", Proceedings of Interflam 2010, 2010, pp. 281-290.

[49] Zhubanov, T., and Gibov, K., (1988) Oxygen Index and Minimum Limiting Rates of Polymer Combustion, Fire and Materials 12: 169-172, http://dx.doi.org/10.1002/fam.810120406

[50] Stoliarov, S., and Walters, R., (2008) Determination of the heats of gasification of polymers using differential scanning calorimetry, Polymer Degradation and Stability 93: 422-427, http://dx.doi.org/10.1016/j.polymdegradstab.2007.11.022 